\title{
Diabetic Painful and Insensate Neuropathy: Pathogenesis and Potential Treatments
}

\author{
Irina G. Obrosova \\ Pennington Biomedical Research Center, Louisiana State University System, Baton Rouge, Louisiana 70808
}

\begin{abstract}
Summary: Advanced peripheral diabetic neuropathy (PDN) is associated with elevated vibration and thermal perception thresholds that progress to sensory loss and degeneration of all fiber types in peripheral nerve. A considerable proportion of diabetic patients also describe abnormal sensations such as paresthesias, allodynia, hyperalgesia, and spontaneous pain. One or several manifestations of abnormal sensation and pain are described in all the diabetic rat and mouse models studied so far (i.e., streptozotocin-diabetic rats and mice, type 1 insulinopenic $\mathrm{BB} /$ Wor and type 2 hyperinsulinemic diabetic $\mathrm{BBZDR} /$ Wor rats, Zucker diabetic fatty rats, and nonobese diabetic, Akita, leptin- and leptin-receptor-deficient, and highfat diet-fed mice). Such manifestations are 1) thermal hyperalgesia, an equivalent of a clinical phenomenon described in early PDN; 2) thermal hypoalgesia, typically present in advanced PDN; 3) mechanical hyperalgesia, an equivalent of pain on pressure in early PDN; 4) mechanical hypoalgesia, an equivalent to the loss of sensitivity to mechanical noxious stimuli in advanced PDN; 5) tactile allodynia, a painful perception of a
\end{abstract}

light touch; and 5) formalin-induced hyperalgesia. Rats with short-term diabetes develop painful neuropathy, whereas those with longer-term diabetes and diabetic mice typically display manifestations of both painful and insensate neuropathy, or insensate neuropathy only. Animal studies using pharmacological and genetic approaches revealed important roles of increased aldose reductase, protein kinase $\mathrm{C}$, and poly(ADPribose) polymerase activities, advanced glycation end-products and their receptors, oxidative-nitrosative stress, growth factor imbalances, and C-peptide deficiency in both painful and insensate neuropathy. This review describes recent achievements in studying the pathogenesis of diabetic neuropathic pain and sensory disorders in diabetic animal models and developing potential pathogenetic treatments. Key Words: Animal models, diabetic insensate neuropathy, diabetic painful neuropathy, formalin-induced hyperalgesia, mechanical hyper- and hypoalgesia, pathogenetic treatments of diabetic neuropathic pain and sensory loss, symptomatic treatments of diabetic pain, tactile allodynia, thermal hyper- and hypoalgesia.

\section{DIABETIC PAIN AND SENSORY LOSS: PREVALENCE, CURRENT TREATMENT OPTIONS, AND LIMITATIONS OF EXISTING ANIMAL MODELS}

Diabetic distal symmetric sensorimotor polyneuropathy, typically referred to as peripheral diabetic neuropathy (PDN), affects at least $50 \%$ of diabetic patients in the United States, and is the leading cause of foot amputation. ${ }^{1,2}$ Advanced PDN is associated with elevated vibration and thermal perception thresholds that progress to sensory loss, occurring in conjunction with degeneration of all fiber types in the peripheral nerve. A proportion of patients with PDN also describe abnormal sensations such as paresthesias, allodynia, hyperalgesia, and

Address correspondence and reprint requests to: Irina G. Obrosova, Ph.D., Pennington Biomedical Research Center, Louisiana State University System, 6400 Perkins Road, Baton Rouge, LA 70808. E-mail: obrosoig@pbrc.edu. spontaneous pain that sometimes seriously affect their quality of life. ${ }^{3}$ The prevalence of pain varies from $10 \%$ to $20 \%$ in subjects with diabetes mellitus and from $40 \%$ to $50 \%$ in those with diabetic neuropathy. ${ }^{4}$ As A.I. Vinik put it, "Pain in neuropathy is multifactorial and can occur at different levels, starting at the peripheral sympathetic nervous system in the skin ( $\mathrm{C}$ fibers) and migrating to involve $\mathrm{A} \beta$ and $\mathrm{A} \delta$ fibers to produce allodynia, continuing with reorganization at the cord-level, cold allodynia, and finally, within the central nervous system, spontaneously as opposed to provoked pain." ${ }^{5}$ The natural course of painful diabetic neuropathy is variable, with many patients experiencing spontaneous improvement and resolution of pain. ${ }^{4}$ Except for two pathogenetic drugs (i.e., the aldose reductase inhibitor epalrestat, approved in Japan, and the antioxidant lipoic acid, approved in several countries), current therapeutic options are limited to symptomatic treatment with tricyclic compounds, selective serotonin noradrenaline reuptake inhibitors, anticon- 
vulsants, opiates, capsaicin, and membrane stabilizers. ${ }^{6}$ Several new symptomatic drugs (i.e., the serotonin and norepinephrine reuptake inhibitor duloxetine and two anticonvulsants, pregabalin and gabapentin) have recently been approved for treatment of diabetic neuropathic pain in the United States; however, their use is often associated with problems such as insufficient efficacy, development of adverse side effects, and cost effectiveness. The development of better treatment modalities for diabetic neuropathic pain and sensory loss should be based on pathogenetic mechanisms.

Pathogenesis of diabetic painful neuropathy is poorly studied, although identification of impaired cutaneous endothelium-related vasodilation and C-fiber-mediated vasoconstriction as well as increased sural nerve epineurial blood flow in diabetic subjects with painful, compared to those with painless, neuropathy suggests the importance of hemodynamic factors. ${ }^{7,8}$ A recent study with thalamic proton magnetic resonance spectroscopy implicates thalamic neuronal dysfunction. ${ }^{9}$

Understanding the biochemical mechanisms underlying diabetic neuropathic pain and sensory disorders requires preclinical studies in animal models. Existing animal models of diabetic painful and insensate neuropathy, however, have serious limitations. ${ }^{3}$ Diabetic rats and mice have limited life span and rarely show evidence of overt neuropathy, such as demyelination, axonal degeneration, fiber loss, or axonal regeneration in their peripheral nerves. This makes diabetic rodents unsuitable for studying the contribution of these phenomena of advanced PDN to pain or to loss of sensory function. In addition, it is not possible to quantify spontaneous pain in animals. Nonetheless, despite these limitations, assessment of behavioral responses to external stimuli in diabetic rats and mice (i.e., thermal and mechanical hyper- and hypoalgesia, tactile allodynia, as well as formalin-induced spontaneous nociceptive behavior) has led to identification of a number of mechanisms of abnormal sensation and pain in diabetes. This review summarizes current knowledge on the mechanisms of diabetic painful and insensate neuropathy obtained through the studies in diabetic animal models and describes pathogenetic treatments for diabetic neuropathic pain and sensory loss emerging from experimental studies and clinical trials.

\section{PATHOGENESIS AND EXPERIMENTAL TREATMENTS OF DIABETES-ASSOCIATED THERMAL HYPER- AND HYPOALGESIA}

A considerable proportion of human subjects with PDN display altered cutaneous sensory perception including warm and cold thermal perception, vibration, touch-pressure sensation, and current perception, and vibratory and thermal testing is typically performed during primary screening for diabetic neuropathy and in clinical trials of new therapeutics. ${ }^{10,11}$ Assessment of thermal sensitivity in diabetic rats and mice is performed using a number of behavioral tests, among which paw withdrawal, tail flick, and hot-plate tests are the most widely used.

The tail flick test, which does not have an anatomical equivalent in humans, measures the latency for tail movement from an escalating radiant heat source and reflects activity of a simple spinal reflex arc, thus providing information on peripheral nerve and spinal function in isolation from higher nociceptive processing and cognitive systems. The Hargreaves method, with escalating radiant heat stimulation applied to the plantar surface of a single paw, measures the latency of the paw withdrawal from a noxious stimulus source, and includes supraspinal sensory processing. The hot-plate test provides rapid stimulation of all paws, tail, and in some cases-as when used in obese leptin-deficient $(o b / o b)$, leptin receptor-deficient $(d b / d b)$, and high-fat diet-fed mice-parts of abdominal skin. The tail-flick and hotplate tests are less sensitive in detecting thermal hyperor hypoalgesia and effects of experimental therapies in diabetic rats and mice. ${ }^{12-14}$ In general, the hot-plate test is seldom used in diabetic rat studies, although it has been sensitive enough to demonstrate thermal hyperalgesia in several studies. ${ }^{15,16}$

Thermal hyperalgesia has been registered in some patients with mild PDN, whereas advanced-stage disease is typically characterized by elevated thermal perception thresholds (hypoalgesia) that progress to sensory loss, occurring in conjunction with unmyelinated peripheral nerve fiber degeneration. ${ }^{17,18}$ Thus, studies of mechanisms underlying both thermal hyperalgesia and thermal hypoalgesia and the development of agents to prevent and treat both disorders are clinically relevant.

Thermal hyperalgesia has been described in streptozotocin (STZ)-diabetic and Zucker diabetic fatty rats with short-term (2-8 weeks) diabetes, ${ }^{19-22}$ as well as in type 1 insulinopenic BB/Wor and type 2 hyperinsulinemic diabetic BBZDR/Wor rats. ${ }^{23,24}$ This phenomenon develops with participation of multiple pathogenetic mechanisms, including (but not limited to) increased aldose reductase (AR),${ }^{19}$ the advanced glycation end product/receptor for advanced glycation end product (AGE/RAGE) axis, ${ }^{25}$ protein kinase $\mathrm{C}(\mathrm{PKC}),{ }^{26}$ poly(ADP-ribose) polymerase (PARP), ${ }^{12}$ and angiotensin converting enzyme (ACE) activities, ${ }^{22}$ oxidative stress, ${ }^{20,21}$ and C-peptide deficiency. ${ }^{27}$ Thermal hyperalgesia in STZ-diabetic rats was prevented or reversed by the AR inhibitor lidorestat, ${ }^{19}$ the AGE formation inhibitor pyridoxamine, ${ }^{25}$ the PKC LY333531, ${ }^{26}$ several antioxidants (including $\alpha$-lipoic acid, ${ }^{20}$ the hydroxyl radical scavenger dimethylthiourea, ${ }^{21}$ the xanthine oxidase inhibitor allopurinol, ${ }^{28}$ and taurine $^{29}$ ), the PARP inhibitors 1,5 -isoquinolinediol ${ }^{12}$ and nicotinamide, ${ }^{30}$ and the neurocytokine interleukin- 
$6,{ }^{31}$ as well as by transgene-mediated expression of enkephalin in dorsal root ganglia neurons. ${ }^{32} \mathrm{C}$-peptide and the glutamate carboxypeptidase II inhibitor treatments alleviated thermal hyperalgesia in type 1 diabetic $\mathrm{BB} /$ Wor rats, ${ }^{27,33}$ and taurine in type 2 Zucker diabetic fatty rats. $^{34}$

Whereas mechanisms underlying analgesic effect of these agents require further studies, a number of the treatments mentioned here have been reported to counteract glutamate excitotoxicity by reducing glutamate accumulation, ${ }^{33,35,36}$ to restore impaired $\mathrm{Ca}^{2+}$ homeostasis and signaling, ${ }^{37}$ to inhibit mitogen-activated protein kinase (MAPK) activation, ${ }^{38}$ and to counteract production of proinflammatory cytokines. ${ }^{39}$ All these biochemical changes are involved in generation of pain. ${ }^{40-43}$ Enkephalin has been shown to activate the presynaptic $\delta$-opioid receptor and, through inhibition of PKC and p38 MAPK, to prevent the increase in the neuronal $\mathrm{Na}_{\mathrm{V}} 1.7$ tetrodotoxin-sensitive voltage-gated sodium channel isoform (which plays a critical role in nociception) in dorsal root ganglia. ${ }^{32}$

Thermal hypoalgesia is present in a large proportion of patients with advanced PDN. This condition has been described in STZ-diabetic rats with longer-term $(\geq 12$ weeks) diabetes, ${ }^{19,44}$ and in a number of diabetic mouse models, including SVEV129 $\times$ C57BL/6, ${ }^{45} \mathrm{C} 57 \mathrm{Bl} /$ $6 \mathrm{~J},{ }^{13,14,46,47}$ Swiss Webster, ${ }^{48-50}$ 129S1/SvImJ, ${ }^{44}$ and $\mathrm{CD} 1^{51}$ mice made diabetic with STZ, as well as nonobese diabetic (NOD) mice, ${ }^{52}$ leptin-deficient $(o b / o b)$ mice, ${ }^{53,54}$ and diabetic Akita mice (V.R. Drel and I.G. Obrosova, unpublished data), as well as in two animal models of prediabetes and obesity, Zucker fatty rats ${ }^{55}$ and high-fat diet-fed C57B1/6J mice. ${ }^{56}$ Data for leptin receptor-deficient $(d b / d b)$ mice $e^{57,58}$ and Zucker diabetic fatty rats ${ }^{59,60}$ are contradictory, and both normal and reduced thermal sensation in these two animal models have been reported.

Surprisingly, a number of mechanisms contributing to increased thermal sensitivity in the rat models with relatively short-term duration of diabetes were also implicated in development of thermal hypoalgesia in rats with diabetes of longer duration or diabetic mice. Those include increased AR activity, ${ }^{19}$ activation of the AGE/ RAGE axis, ${ }^{25,45,48}$ and oxidative-nitrosative stress, ${ }^{13,14,47,53}$ as well as activation of $\mathrm{ACE}^{22,61}$ and PARP. ${ }^{12,44}$ Several studies, including one identifying an important role of insulin signaling, ${ }^{51}$ implicate neurotrophic factor deficiency in diabetes-induced thermal sensory loss. Correspondingly, a number of pharmacological agents and neurotrophic factors showed efficacy against this disorder. Thermal hypoalgesia in STZ-diabetic rats and $o b / o b$ mice was prevented or alleviated by AR inhibitors. ${ }^{19,53}$ A number of pharmacological agents increased or normalized thermal response latencies in STZ-diabetic rats and mice: peroxynitrite decomposition catalysts, ${ }^{13,46}$ the PARP inhibitor
10-(4-methyl-piperazin-1-ylmethyl)-2H-7-oxa-1,2-diazabenzo[de]anthracen-3-one (GPI-15427), ${ }^{44}$ and the $12 / 15$ lipoxygenase inhibitors cinnamyl-3,4-dihydroxy- $\alpha$-cyanocinnamate ${ }^{62}$ and baicalein, as well as Schwann cell-derived ciliary neurotrophic factor, ${ }^{19}$ TX14(A) (a neurotrophic peptide deriving from prosaposin), ${ }^{63}$ and a sonic hedgehog-IgG fusion protein. ${ }^{64}$ A prolonged expression of neurotrophin-3 in mice, achieved by herpes simplex virus (HSV)-mediated gene transfer with gene expression under the control of an HSV latency promoter, provided protection against diabetes-associated thermal hypoalgesia over a 6 -month period. ${ }^{50} \mathrm{~A}$ peroxynitrite decomposition catalyst treatment also counteracted thermal hypoalgesia in the $o b / o b$ mouse model. ${ }^{47}$ An ACE inhibitor (enalapril) and a hydroxymethylglutaryl-CoA reductase inhibitor (rosuvastatin) alleviated thermal sensory loss in Zucker fatty rats. ${ }^{61}$ The vasopeptidase (i.e., ACE and neutral endopeptidase) inhibitor AVE7688 improved thermal nociception in Zucker diabetic fatty rats. ${ }^{59}$ Finally, thermal hypoalgesia associated with alimentary obesity and glucose intolerance can be cured by switching from high-fat to normal-fat diet. ${ }^{56}$ Thus, both dietary and pharmacological approaches should be developed for treatment of this disorder in human subjects with diabetes mellitus.

Until recently, for lack of objective measures, smallcaliber nerve fiber degeneration has not been evaluated in either human subjects with diabetes mellitus or animal models. Emerging new techniques such as corneal confocal microscopy, a reiterative, rapid, noninvasive in vivo imaging technique for quantitative assessment of degeneration and regeneration of corneal nerve fibers, ${ }^{65,66}$ and skin biopsy with visualization and quantitation of epidermal nerve fibers ${ }^{67-69}$ have generated enormous potential for a better understanding the mechanisms underlying small nerve fiber degeneration, a phenomenon that may ultimately lead to a complete loss of sensory function and that is a major cause of foot amputation.

Clinical studies revealed that subjects with both type 1 and type 2 diabetes exhibit epidermal nerve fiber loss. ${ }^{67-69}$ In diabetic patients, distal leg intraepidermal nerve fiber density showed significant negative correlations with warm and cold thermal threshold, heat pain, pressure sense, neurological disability score, total sensory score, and total neuropathy score. ${ }^{68}$ In another study, intraepidermal nerve fiber density, branch density, and branch length showed a progressive reduction with increasing severity of neuropathy, which was significant in diabetic patients with mild, moderate, and severe neuropathy. ${ }^{66}$

Corneal confocal microscopy showed a progressive reduction in corneal nerve fiber density and branch density, but the latter was significantly reduced even in diabetic patients without neuropathy. ${ }^{66}$ Both intraepidermal and corneal nerve fiber densities correlated signifi- 
cantly with cold detection and heat as pain thresholds. Intraepidermal and corneal nerve fiber lengths were reduced in patients with painful, compared with painless, diabetic neuropathy. Whereas studies of corneal nerve fibers have never been performed in animal models of diabetes, evidence for reduced intraepidermal nerve fiber density in a number of diabetic animal models in emerging. In particular, this phenomenon was described in STZ-diabetic ${ }^{44}$ and Zucker diabetic fatty rats ${ }^{60}$ and in $\mathrm{C} 57 \mathrm{Bl} / 6 \mathrm{~J},{ }^{13,14,46,47,70}$ Swiss Webster, ${ }^{48,49} 129 \mathrm{~S} 1 / \mathrm{SvImJ},{ }^{44}$ C57B6:129S7, ${ }^{71}$ and $\mathrm{CD} 1^{51}$ mice made diabetic with STZ, as well as in leptin-deficient $(o b / o b)^{53,54}$ and leptin receptor-deficient $(\mathrm{d} b / \mathrm{db})$ mice. ${ }^{57}$ Note that high-fat diet-fed mice with impaired glucose tolerance and obesity, but without overt hyperglycemia, do not display any intraepidermal fiber loss, ${ }^{56}$ similarly to human subjects with metabolic syndrome. ${ }^{72}$

Is intraepidermal nerve fiber density a reliable morphological correlate of thermal algesia in diabetic animal models? From a neurotherapeutic discovery perspective, should a candidate drug for treatment of abnormal thermal sensation associated with PDN be necessarily effective on physiological measures of both thermal sensitivity and intraepidermal nerve fiber density? Taking into consideration that small sensory nerve fiber loss may be a difficult condition to reverse, especially in human subjects with advanced diabetic neuropathy, is it possible to, at least partially, correct diabetes-induced thermal hypoalgesia by agents that fail to induce small sensory nerve fiber regeneration? An answer to several of these questions has been obtained in recent animal studies. Thermal hypoalgesia was shown to develop prior to small sensory nerve fiber degeneration in STZ-diabetic $\mathrm{C} 57 \mathrm{Bl} / 6 \mathrm{~J}$ mice, ${ }^{46}$ an observation later reproduced in the STZ-diabetic Swiss Webster mouse model. ${ }^{49}$ Zucker diabetic fatty rats displayed intraepidermal nerve fiber loss in the absence of thermal hypoalgesia. ${ }^{60}$ Furthermore, a peroxynitrite decomposition catalyst treatment alleviated thermal hypoalgesia, but not intraepidermal nerve fiber loss, in $o b / o b$ mice. $^{54}$ In another study, STZ-diabetic 12/15-lipoxygenase-deficient mice exhibited less severe thermal and mechanical hypoalgesia than did STZ-diabetic wild-type $(\mathrm{C} 57 \mathrm{Bl} / 6 \mathrm{~J})$ mice, whereas diabetes-related reduction in intraepidermal nerve fiber density was similar in both groups. ${ }^{73}$ All these findings suggest that 1) intraepidermal nerve fiber loss is not an exactly reliable correlate of thermal hypoalgesia in diabetic animal models; 2) the process of drug discovery for diabetic sensory neuropathy should not heavily rely on intraepidermal nerve fiber density as a measure of therapeutic efficacy of candidate agents; and 3) pharmacological studies related to diabetic abnormal sensation and pain should not necessarily include intraepidermal nerve fiber density as an endpoint.

\section{PATHOGENESIS AND EXPERIMENTAL TREATMENTS: DIABETES-ASSOCIATED MECHANICAL HYPER- AND HYPOALGESIA}

Mechanical hyperalgesia and hypoalgesia have both been reported in human subjects with diabetes mellitus. In a recent study, mechanical hyperalgesia (pain on pressure) has been identified in $71 \%$ of human subjects with early PDN. ${ }^{74}$ In contrast, patients with advanced PDN typically have elevated vibration perception thresholds indicative of sensory loss, a condition ultimately responsible for foot ulceration and amputation. ${ }^{75,76}$ Thus, studies of mechanical hyper- and hypoalgesia and development of agents to prevent and treat both disorders have clinical relevance. In experimental studies, mechanical withdrawal thresholds in diabetic rat and mouse models are assessed by paw (rats) and tail (mouse) pressure Randall-Selitto test or with a von Frey aesthesiometer and rigid von Frey filaments. Mechanical hyperalgesia has been reported in both STZ-diabetic ${ }^{20,21,30,77,78}$ and Zucker diabetic fatty rats, ${ }^{34,79}$ in which pressure pain preceded development of type 2 diabetes. In contrast,

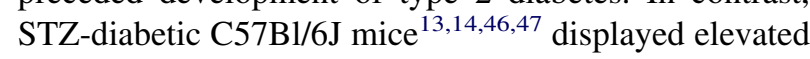
mechanical withdrawal thresholds. Several hyperglycemia-related mechanisms, i.e., increased AR activity, ${ }^{77}$ oxidative-nitrosative stress, ${ }^{78}$ and PARP activation, ${ }^{12,44}$ as well as impaired insulin signaling ${ }^{79}$ have been implicated in pain on pressure in diabetic and prediabetic rat models. Correspondingly, diabetes-induced mechanical hyperalgesia in STZ-diabetic rats was corrected or alleviated by $\mathrm{AR}$ inhibitors, ${ }^{77,80}$ by antioxidants ( $\alpha$-lipoic acid, ${ }^{20}$ dimethylthiourea, ${ }^{21}$ allopurinol, ${ }^{29}$ and taurine ${ }^{30}$ ), and by a peroxynitrite decomposition catalyst, ${ }^{78}$ as well as by PARP inhibitors, ${ }^{12,44}$ PARP inhibitor-containing combination therapies, ${ }^{22}$ and the $\mathrm{Na}^{+} / \mathrm{H}^{+}$-exchanger-1 inhibitor cariporide. ${ }^{81}$ Gabapentin (an anticonvulsant agent) and insulin strongly elevated the nociceptive threshold in STZ-diabetic rats, but gabapentin elevated it above normal levels. ${ }^{82}$ In the same study, OT-7100 (5n-butyl-7-(3,4,5-trimethoxybenzoylamino)pyrazolo[1,5$\alpha$ ]pyrimidine) counteracted mechanical hyperalgesia in a dose-dependent manner. Rosuvastatin ${ }^{83}$ the PKC inhibitor LY333531, ${ }^{26}$ and interleukin- $6,{ }^{31}$ which corrected other manifestations of peripheral diabetic neuropathy, including thermal hyperalgesia, did not reduce an exaggerated sensitivity to mechanical noxious stimuli. Notably, two other PKC inhibitors, staurosporine and protein kinase $\mathrm{C}$ pseudosubstrate inhibitor peptide [PKC(1936)], elevated mechanical nociceptive thresholds in STZdiabetic rats in a dose-dependent manner without altering nociceptive threshold in control rats. ${ }^{84}$ Taurine also alleviated mechanical hyperalgesia in Zucker diabetic fatty rats. ${ }^{34}$ Several agents, including peroxynitrite decomposition catalysts ${ }^{13,46}$ and 12/15-lipoxygenase inhibitors, ${ }^{62}$ alleviated mechanical hypoalgesia in STZ-diabetic mice. 
PARP gene deficiency was associated with the absence of mechanical hypoalgesia that was clearly manifest in the corresponding wild-type STZ-diabetic mice, ${ }^{44}$ and 12/15-lipoxygenase gene deficiency was partially protective in the same mouse model. ${ }^{73}$

\section{DIABETES-ASSOCIATED TACTILE ALLODYNIA}

In addition to spontaneous pain, painful diabetic neuropathy in human subjects is also characterized by the development of tactile allodynia, a condition in which light touch is perceived as painful. Tactile allodynia is observed in a considerable proportion $(30 \%-47 \%)$ of human subjects with diabetes mellitus. ${ }^{10,85}$ A similar phenomenon is observed in STZ-diabetic rats, in which the light touch $(<15 \mathrm{~g})$ of von Frey filaments or the light stroking of a paw induces a withdrawal response from the stimulus. ${ }^{86}$ In diabetic mouse models, the findings on tactile sensitivity are contradictory. One research group found tactile allodynia in STZ-diabetic C57B1/6J and $129 \mathrm{~S} 1 / \mathrm{SvImJ}$ mice, and diabetic Akita mice, as well in as $o b / o b$ mice (a model of type 2 diabetes) and high-fat diet-fed mice (a model of prediabetes and alimentary obesity). ${ }^{13,14,44,46,47,53,54,56}$ Tactile allodynia has also been described in STZ-diabetic B6129PF2/J87 and CD1 mice. ${ }^{51,87}$ Others found reduced tactile sensitivity, rather than tactile allodynia, in STZ-diabetic C57B1/6J mice and $d b / d b$ mice. ${ }^{58,70}$ Tactile allodynia also develops in nerve injury models of neuropathic pain ${ }^{88-90}$ (e.g., in the model of sciatic nerve ischemia ${ }^{90}$ ).

The mechanisms underlying diabetes-induced tactile allodynia have not been studied in detail, although considerable progress has been made in experimental studies performed in the last several years. Tactile allodynia associated with early PDN in STZ-diabetic rats was alleviated by peroxynitrite decomposition catalyst ${ }^{78}$ and PARP inhibitor ${ }^{12,44}$ treatments, which suggests the involvement of nitrosative stress and PARP activation. The latter is consistent with less severe or absent tactile allodynia in STZ-diabetic inducible nitric oxide synthasedeficient and PARP-deficient mice, compared with the corresponding wild-type mice with STZ-diabetes of similar severity and duration. ${ }^{14,44}$ Other agents effective against tactile allodynia in STZ-diabetic rat model include nitecapone, a catechol- $O$-methyltransferase inhibitor with potent antioxidant properties, ${ }^{91}$ agmatine, an endogenous cationic amine resulting from the decarboxylation of L-arginine, ${ }^{92}$ allopurinol, ${ }^{28}$ interleukin- $6,{ }^{31}$ melatonin, ${ }^{93}$ benfotiamine, ${ }^{94}$ and the cannabinoid agonist WIN 55,212-2, ${ }^{95}$ as well as a cocktail of $\mathrm{B}_{1}, \mathrm{~B}_{6}$, and $\mathrm{B}_{12}$ vitamins. ${ }^{96}$ Tactile allodynia in STZ-diabetic mice was found preventable by sulfasalazine, probably via blockage of NF- $\kappa$ B activation, ${ }^{87}$ as well as the cyclooxygenase-2 inhibitor meloxicam ${ }^{97}$ and the 12/15-lipoxy- genase inhibitors baicalein and cinnamyl-3,4-dihydroxy$\alpha$-cyanocinnamate. ${ }^{62}$

\section{SPONTANEOUS INFLAMMATORY DIABETIC NEUROPATHIC PAIN}

The mechanical and thermal behavioral tests described above provide acute sensory stimuli and represent measures of the threshold to nociceptive pain that is transduced by myelinated and unmyelinated fibers, respectively. The formalin test principally differs from both as the second phase of the flinching response occurs despite minimal input to the spinal cord from primary afferent nociceptors. ${ }^{3}$ Thus, the test can be used for studying spontaneous inflammatory nociceptive behavior in pathological conditions, including diabetes. In animal models, whereas STZ-diabetic rats display exaggerated flinching behavior in both the first and second phases of the formalin test, ${ }^{12}$ STZ-diabetic mice lack the second phase $^{98}$ and are, therefore, unsuitable for the studies of spontaneous tonic pain associated with diabetes.

Several pathogenetic mechanisms have been implicated in formalin-induced hyperalgesia in STZ-diabetic rats. Those include increased activities of $\mathrm{AR},{ }^{99}$ PARP, ${ }^{1,44}$ and cyclooxygenase- $2{ }^{99}$; impaired neurotrophic support ${ }^{100}$; and increase in the inhibitory neurotransmitter GABA and depletion of spinal potassium-chloride cotransporters. ${ }^{101}$ Correspondingly, diabetes-associated formalin-induced hyperalgesia was suppressed by several $\mathrm{AR}^{99,102}$ and PARP ${ }^{12,44}$ inhibitors, prosaposin-derived peptide, ${ }^{100}$ and the $\mathrm{GABA}_{\mathrm{A}}$ receptor antagonist bicuculline ${ }^{101}$ as well as insulin, ${ }^{103}$ gabapentin, ${ }^{104}$ and a $\mathrm{B}_{1}, \mathrm{~B}_{6}$, and $\mathrm{B}_{12}$ vitamin cocktail. ${ }^{96}$

\section{SUMMARY OF THE CURRENT KNOWLEDGE ON THE KEY MECHANISMS OF DIABETIC PAINFUL AND INSENSATE NEUROPATHY AND CLINICAL STUDIES OF PATHOGENETIC AND NEW SYMPTOMATIC TREATMENTS}

An analysis of the literature on neuropathic sensory disorders and pain in diabetic animal models unravels key pathogenetic mechanisms implicated in several types of hyperalgesia and abnormal sensation. Those include increased AR activity, oxidative-nitrosative stress, protein kinase C, PARP and ACE activations, C-peptide deficiency, impaired neurotrophism, and proinflammatory response (probably mediated by cyclooxygenase-2, 12/15-lipoxygenase, and NF- $\kappa \mathrm{B}$ activations).

The importance of increased AR activity has been confirmed in several clinical trials of AR inhibitors. In particular, a 52-week multicenter (78 centers in Japan) placebo-controlled double-blind parallel group study of the AR inhibitor fidarestat in 279 patients with type 1 and 
type 2 diabetes and associated peripheral neuropathy revealed beneficial effects of treatment on subjective symptoms including numbness, spontaneous pain, sensation of rigidity, paresthesia in the sole upon walking, heaviness in the foot, and hypesthesia. ${ }^{105}$ Similar results have been achieved in the 3-year, multicenter (112 centers in Japan), comparative Aldose Reductase InhibitorDiabetes Complications Trial in 594 subjects with diabetic neuropathy, in which numbness of limbs, sensory abnormalities, and cramping were alleviated in patients treated with the AR inhibitor epalrestat compared with the placebo group. ${ }^{106} \mathrm{~A}$ more recent open-label pilot study (12 hospitals in Japan, 22 patients) revealed beneficial effect of fidarestat on vibration perception threshold of the upper and lower limbs and subjective symptoms of PDN, such as severity of numbness in the lower limbs, heaviness in the foot, coldness and hot flushes in the lower limbs, smarting pain causing difficulty in walking, sensation as if walking on sand, sensation as if walking on an uneven road, spontaneous pain in the lower limbs, and dizziness. ${ }^{107}$ The clinical trial of another AR inhibitor, ranirestat, revealed improvement of vibration perception threshold in subjects with diabetic neuropathy. ${ }^{108}$ Beneficial effects on signs and symptoms of abnormal sensation and neuropathic pain have been reported in clinical studies with other agents affecting pathogenetic mechanisms of disease. ${ }^{109}$ In particular, a 6-month, randomized, double-masked, placebo-controlled study of the PKC- $\beta$ inhibitor ruboxistaurin revealed beneficial effect of treatment on Neuropathy Total Symptom Score-6, which quantifies frequency and intensity of aching, burning, prickling and lancinating pain, numbness, and allodynia in patients' feet and legs as well as symptom subscore and total score of Norfolk Quality-of-Life Questionnaire for Diabetic Neuropathy (composed of questions related to patients' signs and symptoms, as well as to the impact of PDN on patients' activities of daily life. ${ }^{110}$ The SYDNEY trial of $\alpha$-lipoic acid, $600 \mathrm{mg} \mathrm{d}^{-1}$, in 120 subjects with symptomatic diabetic sensorimotor polyneuropathy demonstrated significant improvement of the Total Symptom Score (TSS), a measure of positive neuropathic sensory symptoms, as well as of each TSS item (lancinating and burning pain, asleep numbness and prickling). ${ }^{11}$ The SYDNEY 2 trial in 181 subjects with PDN revealed efficacy of three doses of $\alpha$-lipoic acid $\left(600,1200\right.$, and $\left.1800 \mathrm{mg} \mathrm{d}^{-1}\right)$ in improving the TSS, stabbing and burning pain, the Neuropathy Symptoms and Change Score, and the patients' global assessment of efficacy of treatment. ${ }^{112}$ A double-blind, placebo-controlled, randomized multicenter study in 161 type 1 diabetes patients with diabetic distal symmetric polyneuropathy revealed beneficial effect of C-peptide on vibration perception thesholds. ${ }^{113}$ Another study revealed beneficial effect of the ACE inhibitor lisinopril on temperature discrimination and vibration perception thresholds in diabetic subjects with hypertension. ${ }^{114}$
Several drug candidates for the treatment of diabetic neuropathic pain are emerging from recent clinical studies of nonpathogenetic therapies. Two randomized, double-blind, placebo-controlled studies of lamotrigine, an anticonvulsant drug used in the treatment of epilepsy, in patients with painful diabetic neuropathy (each study with $n=360$ ) revealed greater reduction in pain-intensity score in patients receiving lamotrigine $400 \mathrm{mg}$, compared with the placebo-treated group. ${ }^{115}$ Another anticonvulsant drug, topiramate, was found effective in promoting pain relief in subjects with moderately to severe painful neuropathy. ${ }^{116}$ Lacosamide, $400 \mathrm{mg}$, an enhancer of slow inactivation of voltage gated sodium channels, caused a statistically significant (over placebo) improvement in Likert pain score in the multicenter, randomized, placebo-controlled, double-blind trial of two doses of this agent in subjects with painful neuropathy. ${ }^{117} \mathrm{~A}$ randomized, blinded trial of intramuscular gene transfer using plasmid vascular endothelial growth factor to treat diabetic polyneuropathy $(n=50)$ reveal efficacy against both sensory loss and diabetic neuropathic pain. ${ }^{118}$

\section{STRATEGIES FOR DRUG DISCOVERY}

A recent characterization of manifestations of small sensory fiber neuropathy in diabetic rat and mouse models facilitates selection of appropriate animal models for studying diabetic painful and insensate neuropathy. Early diabetic rat models such as STZ-diabetic and Zucker diabetic fatty rats are suitable for studies of thermal hyperalgesia and pain on pressure characteristic for early PDN, and the STZ-diabetic model is also appropriate for studies of tactile allodynia and spontaneous pain (formalin-induced hyperalgesia). Rats with longer duration of STZ-diabetes, as well as STZ-diabetic $o b / o b$ mice and high-fat diet-fed mice, represent good models for studying thermal and mechanical hypoalgesia characteristic of advanced PDN in humans (insensate neuropathy). Discovery of new drug targets for treatment of diabetic neuropathic pain and sensory loss should be conducted using appropriate animal models.

An analysis of the literature on experimental peripheral diabetic neuropathy suggests that, to date, all of the pharmacological agents shown to counteract one or several manifestations of painful or insensate neuropathy also have efficacy against nerve conduction velocity deficit. Note, however, that the number of experimental diabetic neuropathy-related studies with motor and sensory nerve conduction velocities as endpoints greatly exceeds the number of those in which nerve conduction measurements were combined with assessment of functional indices of small sensory fiber neuropathy. There is, therefore, a high probability that the agents previously demonstrated to prevent or reverse nerve conduction def- 
icit associated with experimental PDN will also be effective against diabetes-related sensory disorders.

Diabetic neuropathic pain and sensory loss represent manifestations of chronic complications of diabetes or end-organ disease that affects the cardiovascular system, ocular lens and retina, renal cortex, and somatic and autonomic nervous systems. Studies in diabetic animal and cell culture models revealed that many pathogenetic mechanisms implicated in diabetic endothelial and myocardial dysfunction, neuropathy, nephropathy, retinopathy, and cataract are similar. In particular, numerous reports suggest the importance of increased AR, PKC, and PARP activities, nonenzymatic glycation/glycoxidation, and oxidative stress in the development of diabetic cardiovascular disease, ocular complications, and nephropathy, as well as diabetic painful and/or insensate neuropathy. It is therefore reasonable to test any new prospective pathogenetic treatments emerging from experimental studies related to other diabetic complications on indices of sensation and pain.

Valuable information regarding potential mechanisms of diabetic neuropathic pain and abnormal sensory responses, as well as new drug targets, can be obtained from studies in other (nondiabetic) models of neuropathic pain, provided that these models develop pathobiochemical changes similar to those in diabetes. For example, glutamate excitotoxicity has been implicated both in diabetic neuropathic pain ${ }^{33,119}$ and in neuropathic pain caused by other mechanisms, ${ }^{120,121}$ and STZ-diabetic rats accumulate glutamate in their peripheral nerves. ${ }^{35,36}$ Glutamate concentrations in the peripheral nerve system are reduced by AR inhibitor, ${ }^{35}$ vasodilator, ${ }^{122}$ and antioxidant ${ }^{123}$ treatments-and all these treatments also alleviate symptoms of diabetic neuropathic pain in diabetic animal models ${ }^{19,20-22,77,78,99,102}$ and in human subjects. ${ }^{105-107,111,112,114,124}$ Several reports indicate that the pro-inflammatory cytokine tumor necrosis factor alpha (TNF- $\alpha$ ) plays a role in nondiabetic painful neuropathy. ${ }^{125-127}$ It is quite plausible that it also plays a role in diabetic neuropathic pain (as has been suggested ${ }^{128,129}$ ), because TNF- $\alpha$ expression is increased in tissues of diabetic animals, and TNF- $\alpha$ induces overexpression of cyclooxygenase- $2,{ }^{130,131}$ also implicated in diabetic hyperalgesia and allodynia. ${ }^{97,99}$ TNF- $\alpha$ antagonists have never been tested in models of diabetic painful neuropathy. Other mechanisms contributing to neuropathic pain include activation of MAPKs (p38-MAPK) in spinal microglia, ${ }^{132}$ Schwann cells, ${ }^{133}$ and macrophages ${ }^{133}$ and altered calcium homeostasis and signaling in neurons. ${ }^{134}$ These pathobiochemical changes have been documented in diabetes, ${ }^{29,132}$ which provides a rationale for evaluation of p38 MAPK inhibitors and calcium antagonists in diabetic painful neuropathy.

In conclusion, despite limitations of existing animal models for studying diabetic neuropathic pain and sensory loss, evaluation of experimental behavioral correlates of clinical endpoints in diabetic animal models has dissected a number of pathogenetic mechanisms implicated in diabetic painful and insensate neuropathy. The important roles for increased aldose reductase and protein kinase $\mathrm{C}$ activities and enhanced oxidative stress originally revealed in experimental studies have been confirmed in clinical trials in subjects with diabetic sensorimotor polyneuropathy. New drug candidates for potential pathogenetic treatments of diabetic neuropathic pain and sensory loss can be identified through specific studies in adequate animal models, as well as analysis of the literature related to diabetic neuropathy, other diabetic complications, and peripheral neuropathic pain in conditions other than diabetes.

\section{REFERENCES}

1. Diabetes in America. 2nd ed. NIH Publication 95-1468. Washington, DC: National Institutes of Health, National Institute of Diabetes and Digestive and Kidney Diseases, 1995.

2. Boulton AJ. The diabetic foot: from art to science. The 18th Camillo Golgi lecture. Diabetologia 2004;47:1343-1353.

3. Calcutt NA. Potential mechanisms of neuropathic pain in diabetes. Int Rev Neurobiol 2002;50:205-208.

4. Veves A, Backonja M, Malik RA. Painful diabetic neuropathy: epidemiology, natural history, early diagnosis, and treatment options. Pain Med 2008;9:660-674.

5. Vinik AI. Advances in diabetes for the millennium: new treatments for diabetic neuropathies. MedGenMed 2004;6(3 Suppl):12.

6. Tesfaye S. Advances in the management of diabetic peripheral neuropathy. Curr Opin Support Palliat Care 2009;3:136-143.

7. Quattrini C, Harris ND, Malik RA, Tesfaye S. Impaired skin microvascular reactivity in painful diabetic neuropathy. Diabetes Care 2007;30:655-659.

8. Eaton SE, Harris ND, Ibrahim S, et al. Increased sural nerve epineurial blood flow in human subjects with painful diabetic neuropathy. Diabetologia 2003;46:934-939.

9. Selvarajah D, Wilkinson ID, Emery CJ, et al. Thalamic neuronal dysfunction and chronic sensorimotor distal symmetrical polyneuropathy in patients with type 1 diabetes mellitus. Diabetologia 2008;51:2088-2092.

10. Vinik AI, Suwanwalaikorn S, Stansberry KB, Holland MT, McNitt PM, Colen LE. Quantitative measurement of cutaneous perception in diabetic neuropathy. Muscle Nerve 1995;18:574-584.

11. Ziegler D, Siekierka-Kleiser E, Meyer B, Schweers M. Validation of a novel screening device (NeuroQuick) for quantitative assessment of small nerve fiber dysfunction as an early feature of diabetic polyneuropathy. Diabetes Care 2005;28:1169-1174

12. Ilnytska O, Lyzogubov VV, Stevens MJ, et al. Poly(ADP-ribose) polymerase inhibition alleviates experimental diabetic sensory neuropathy. Diabetes 2006;55:1686-1694.

13. Drel VR, Pacher P, Vareniuk I, et al. Evaluation of the peroxynitrite decomposition catalyst Fe(III) tetra-mesitylporphyrin octasulfonate on peripheral neuropathy in a mouse model of type 1 diabetes. Int J Mol Med 2007;20:783-792.

14. Vareniuk I, Pavlov IA, Obrosova IG. Inducible nitric oxide synthase gene deficiency counteracts multiple manifestations of peripheral neuropathy in a streptozotocin-induced mouse model of diabetes. Diabetologia 2008;51:2126-2133.

15. Gabra BH, Benrezzak O, Pheng LH, et al. Inhibition of type 1 diabetic hyperalgesia in streptozotocin-induced Wistar versus spontaneous gene-prone BB/Worchester rats: efficacy of a selective bradykinin B1 receptor antagonist. J Neuropathol Exp Neurol 2005;64:782-789. 
16. Lopes LS, Pereira SS, Silva LL, et al. Antinociceptive effect of topiramate in models of acute pain and diabetic neuropathy in rodents. Life Sci 2009;84:105-110.

17. Dyck PJ, Dyck PJ, Larson TS, O’Brien PC, Velosa JA; Nerve Growth Factor Study Group. Patterns of quantitative sensation testing of hypoesthesia and hyperalgesia are predictive of diabetic polyneuropathy: a study of three cohorts. Diabetes Care 2000;23: 510-517.

18. Malik RA. Early detection of nerve damage and repair in diabetic neuropathy. Nat Clin Pract Neurol 2008;4:646-647.

19. Calcutt NA, Freshwater JD, Mizisin AP. Prevention of sensory disorders in diabetic Sprague-Dawley rats by aldose reductase inhibition or treatment with ciliary neurotrophic factor. Diabetologia 2004;47:718-724.

20. Cameron NE, Jack AM, Cotter MA. Effect of $\alpha$-lipoic acid on vascular responses and nociception in diabetic rats. Free Radic Biol Med 2001;31:125-135.

21. Cameron NE, Tuck Z, McCabe L, Cotter MA. Effect of the hydroxyl radical scavenger, dimethylthiourea, on peripheral nerve tissue perfusion, conduction velocity and nociception in experimental diabetes. Diabetologia 2001;44:1161-1169.

22. Li F, Drel VR, Szabó C, Stevens MJ, Obrosova IG. Low-dose poly(ADP-ribose) polymerase inhibitor-containing combination therapies reverse early peripheral diabetic neuropathy. Diabetes 2005;54:1514-1522.

23. Stevens MJ, Zhang W, Li F, Sima AA. C-peptide corrects endoneurial blood flow but not oxidative stress in type $1 \mathrm{BB} /$ Wor rats. Am J Physiol Endocrinol Metab 2004;287:E497-E505.

24. Kamiya H, Murakawa Y, Zhang W, Sima AA. Unmyelinated fiber sensory neuropathy differs in type 1 and type 2 diabetes. Diabetes Metab Res Rev 2005;21:448-458.

25. Cameron NE, Gibson TM, Nangle MR, Cotter MA. Inhibitors of advanced glycation end product formation and neurovascular dysfunction in experimental diabetes. Ann N Y Acad Sci 2005;1043: 784-792.

26. Cotter MA, Jack AM, Cameron NE. Effects of the protein kinase $\mathrm{C}_{\mathrm{b}}$ inhibitor LY333531 on neural and vascular function in rats with streptozotocin-induced diabetes. Clin Sci (Lond) 2002;103: 311-321.

27. Kamiya H, Zhang W, Sima AA. C-peptide prevents nociceptive sensory neuropathy in type 1 diabetes. Ann Neurol 2004;56:827835.

28. Inkster ME, Cotter MA, Cameron NE. Treatment with the xanthine oxidase inhibitor, allopurinol, improves nerve and vascular function in diabetic rats. Eur J Pharmacol 2007;561:63-71.

29. Li F, Obrosova IG, Abatan O, et al. Taurine replacement attenuates hyperalgesia and abnormal calcium signaling in sensory neurons of STZ-D rats. Am J Physiol Endocrinol Metab 2005; 288:E29-E36

30. Stevens MJ, Li F, Drel VR, et al. Nicotinamide reverses neurological and neurovascular deficits in streptozotocin diabetic rats. J Pharmacol Exp Ther 2007;320:458-464.

31. Cameron NE, Cotter MA. The neurocytokine, interleukin-6, corrects nerve dysfunction in experimental diabetes. Exp Neurol 2007;207:23-29.

32. Chattopadhyay M, Mata M, Fink DJ. Continuous $\delta$-opioid receptor activation reduces neuronal voltage-gated sodium channel $\left(\mathrm{Na}_{\mathrm{V}} 1.7\right)$ levels through activation of protein kinase $\mathrm{C}$ in painful diabetic neuropathy. J Neurosci 2008;28:6652-6658.

33. Zhang W, Murakawa Y, Wozniak KM, Slusher B, Sima AA. The preventive and therapeutic effects of GCPII (NAALADase) inhibition on painful and sensory diabetic neuropathy. J Neurol Sci 2006;247:217-223.

34. Li F, Abatan OI, Kim H, et al. Taurine reverses neurological and neurovascular deficits in Zucker diabetic fatty rats. Neurobiol Dis 2006;22:669-676.

35. Obrosova IG, Van Huysen C, Fathallah L, Cao XC, Greene DA, Stevens MJ. An aldose reductase inhibitor reverses early diabetes-induced changes in peripheral nerve function, metabolism, and antioxidative defense. FASEB J 2002;16:123-125.

36. Li F, Szabó C, Pacher P, et al. Evaluation of orally active poly(ADP-ribose) polymerase inhibitor in streptozotocin-diabetic rat model of early peripheral neuropathy. Diabetologia 2004;47: $710-717$.

37. Hall KE, Sima AA, Wiley JW. Voltage-dependent calcium currents are enhanced in dorsal root ganglion neurones from the Bio Bred/Worchester diabetic rat. J Physiol 1995;486:313-322.

38. Price SA, Agthong S, Middlemas AB, Tomlinson DR. Mitogenactivated protein kinase $\mathrm{p} 38$ mediates reduced nerve conduction velocity in experimental diabetic neuropathy: interactions with aldose reductase. Diabetes 2004;53:1851-1856.

39. Jagtap P, Szabó C. Poly(ADP-ribose) polymerase and the therapeutic effects of its inhibitors. Nat Rev Drug Discov 2005;4:421440.

40. Lipton SA. Pathologically-activated therapeutics for neuroprotection: mechanism of NMDA receptor block by memantine and S-nitrosylation. Curr Drug Targets 2007;8:621-632.

41. Yamamoto T, Takahara A. Recent updates of N-type calcium channel blockers with therapeutic potential for neuropathic pain and stroke. Curr Top Med Chem 2009;9:377-395.

42. Gaultier A, Arandjelovic S, Li X, et al. A shed form of LDL receptor-related protein-1 regulates peripheral nerve injury and neuropathic pain in rodents. J Clin Invest 2008;118:161-172.

43. Sommer C, Kress M. Recent findings on how proinflammatory cytokines cause pain: peripheral mechanisms in inflammatory and neuropathic hyperalgesia. Neurosci Lett 2004;361:184-187.

44. Obrosova IG, Xu W, Lyzogubov VV, et al. PARP inhibition or gene deficiency counteracts intraepidermal nerve fiber loss and neuropathic pain in advanced diabetic neuropathy. Free Radic Biol Med 2008;44:972-981.

45. Bierhaus A, Haslbeck KM, Humpert PM, et al. Loss of pain perception in diabetes is dependent on a receptor of the immunoglobulin superfamily. J Clin Invest 2004;114:1741-1751.

46. Drel VR, Pacher P, Vareniuk I, et al. A peroxynitrite decomposition catalyst counteracts sensory neuropathy in streptozotocindiabetic mice. Eur J Pharmacol 2007;569:48-58.

47. Vareniuk I, Pacher P, Pavlov IA, Drel VR, Obrosova IG. Peripheral neuropathy in mice with neuronal nitric oxide synthase gene deficiency. Int J Mol Med 2009;23:571-580.

48. Toth C, Rong LL, Yang C, et al. Receptor for advanced glycation end products (RAGEs) and experimental diabetic neuropathy. Diabetes 2008;57:1002-1017.

49. Beiswenger KK, Calcutt NA, Mizisin AP. Dissociation of thermal hypoalgesia and epidermal denervation in streptozotocin-diabetic mice. Neurosci Lett 2008;442:267-272.

50. Chattopadhyay M, Mata M, Goss J, et al. Prolonged preservation of nerve function in diabetic neuropathy in mice by herpes simplex virus-mediated gene transfer. Diabetologia 2007;50:15501558.

51. Francis G, Martinez J, Liu W, et al. Intranasal insulin ameliorates experimental diabetic neuropathy. Diabetes 2009;58:934-945.

52. Obrosova IG, Mabley JG, Zsengellér Z, et al. Role for nitrosative stress in diabetic neuropathy: evidence from studies with a peroxynitrite decomposition catalyst. FASEB J 2005;19:401-403.

53. Drel VR, Mashtalir N, Ilnytska O, et al. The leptin-deficient $(o b / o b)$ mouse: a new animal model of peripheral neuropathy of type 2 diabetes and obesity. Diabetes 2006;55:3335-3343.

54. Vareniuk I, Pavlov IA, Drel VR, et al. Nitrosative stress and peripheral diabetic neuropathy in leptin-deficient (ob/ob) mice. Exp Neurol 2007;205:425-436.

55. Davidson EP, Coppey LJ, Kleinschmidt TL, Oltman CL, Yorek MA. Vascular and neural dysfunctions in obese Zucker rats: effect of AVE7688. Exp Diabetes Res 2009;2009:912327.

56. Obrosova IG, Ilnytska O, Lyzogubov VV, et al. High-fat diet induced neuropathy of pre-diabetes and obesity: effects of "healthy" diet and aldose reductase inhibition. Diabetes 2007;56: $2598-2608$.

57. Vincent AM, Russell JW, Sullivan KA, et al. SOD2 protects neurons from injury in cell culture and animal models of diabetic neuropathy. Exp Neurol 2007;208:216-227.

58. Wright DE, Johnson MS, Arnett MG, Smittkamp SE, Ryals JM. Selective changes in nocifensive behavior despite normal cutaneous axon innervation in leptin receptor-null mutant $(d b / d b)$ mice. J Peripher Nerv Syst 2007;12:250-261. 
59. Oltman CL, Davidson EP, Coppey LJ, Kleinschmidt TL, Yorek MA. Treatment of Zucker diabetic fatty rats with AVE7688 improves vascular and neural dysfunction. Diabetes Obes Metab 2009;11:223-233.

60. Brussee V, Guo G, Dong Y, et al. Distal degenerative sensory neuropathy in a long-term type 2 diabetes rat model. Diabetes 2008;57:1664-1673.

61. Oltman CL, Davidson EP, Coppey LJ, Kleinschmidt TL, Lund DD, Yorek MA. Attenuation of vascular/neural dysfunction in Zucker rats treated with enalapril or rosuvastatin. Obesity (Silver Spring) 2008;16:82-89.

62. Obrosova IG, Vareniuk I, Stavniichuk R, Nadler JL, Drel VR. 12/15-lipoxygenase inhibition and gene deficiency counteract peripheral diabetic neuropathy in mouse models of type 1 and type 2 diabetes. Diabetes 2009;58 Suppl 1:A220 (abstract).

63. Calcutt NA, Freshwater JD, O'Brien JS. Protection of sensory function and antihyperalgesic properties of a prosaposin-derived peptide in diabetic rats. Anesthesiology 2000;93:1271-1278.

64. Calcutt NA, Allendoerfer KL, Mizisin AP, et al. Therapeutic efficacy of sonic hedgehog protein in experimental diabetic neuropathy. J Clin Invest 2003;111:507-514.

65. Malik RA, Kallinikos P, Abbott CA, et al. Corneal confocal microscopy: a non-invasive surrogate of nerve fibre damage and repair in diabetic patients. Diabetologia 2003;46:683-688.

66. Quattrini C, Tavakoli M, Jeziorska M, et al. Surrogate markers of small fiber damage in human diabetic neuropathy. Diabetes 2007; 56:2148-2154.

67. Sumner CJ, Sheth S, Griffin JW, Cornblath DR, Polydefkis M. The spectrum of neuropathy in diabetes and impaired glucose tolerance. Neurology 2003;60:108-111.

68. Pittenger GL, Ray M, Burcus NI, McNulty P, Basta B, Vinik AI. Intraepidermal nerve fibers are indicators of small fiber neuropathy in both diabetic and non-diabetic patients. Diabetes Care 2004;27:1974-1979.

69. Shun CT, Chang YC, Wu HP, et al. Skin denervation in type 2 diabetes: correlations with diabetic duration and functional impairments. Brain 2004;127:1593-1605.

70. Johnson MS, Ryals JM, Wright DE. Early loss of peptidergic intraepidermal nerve fibers in an STZ-induced mouse model of insensate diabetic neuropathy. Pain 2008;140:35-47.

71. Kellogg AP, Wiggin TD, Larkin DD, Hayes JM, Stevens MJ, Pop-Busui R. Protective effects of cyclooxygenase-2 gene inactivation against peripheral nerve dysfunction and intraepidermal nerve fiber loss in experimental diabetes. Diabetes 2007;56:29973005.

72. Pittenger G, Mehrabyan A, Simmons K, Rice A, Barlow P, Vinik A. Small fiber neuropathy is associated with the metabolic syndrome. Metab Syndr Relat Disord 2005;3:113-121.

73. Obrosova IG, Drel VR, Vareniuk I, Stavniichuk R, Nadler JR, Schmidt RE. Different roles of 12/15-lipoxygenase in large and small fiber diabetic peripheral and autonomic neuropathies. J Peripher Nerv Syst 2009, in press (abstract).

74. Otto M, Bak S, Bach FW, Jensen TS, Sindrup SH. Pain phenomena and possible mechanisms in patients with painful polyneuropathy. Pain 2003;101:187-192.

75. Eldor R, Raz I, Ben Yehuda A, Boulton AJ. New and experimental approaches to treatment of diabetic foot ulcers: a comprehensive review of emerging treatment strategies. Diabet Med 2004; 21:1161-1173.

76. Pradhan L, Nabzdyk C, Andersen ND, LoGerfo FW, Veves A. Inflammation and neuropeptides: the connection in diabetic wound healing. Expert Rev Mol Med 2009;11:e2.

77. Dobretsov M, Hastings SL, Romanovsky D, Stimers JR, Zhang JM. Mechanical hyperalgesia in rat models of systemic and local hyperglycemia. Brain Res 2003;960:174-183.

78. Obrosova IG, Drel VR, Oltman CL, et al. Role of nitrosative stress in early neuropathy and vascular dysfunction in streptozotocin-diabetic rats. Am J Physiol Endocrinol Metab 2007;293: E1645-E1655.

79. Romanovsky D, Walker JC, Dobretsov M. Pressure pain precedes development of type 2 disease in Zucker rat model of diabetes. Neurosci Lett 2008;445:220-223.

80. Dobretsov M, Ghaleb AH, Romanovsky D, Pablo CS, Stimers JR.
Impaired insulin signaling as a potential trigger of pain in diabetes and prediabetes. Int Anesthesiol Clin 2007;45:95-105.

81. Miki S, Yoshinaga N, Iwamoto T, Yasuda T, Sato S. Antinociceptive effect of the novel compound OT-7100 in a diabetic neuropathy model. Eur J Pharmacol 2001;430:229-234.

82. Obrosova IG, Ilnytska O, Lyzogubov VV, Mashtalir N, Yorek MA, Drel VR. Activation of $\mathrm{Na}+/ \mathrm{H}+$-exchanger -1 : a novel mechanism in peripheral diabetic neuropathy. In: Abstracts of the 7th International Symposium on Diabetic Neuropathy. Diabet Med 2006;23 Suppl 4 (abstract).

83. Cameron N, Cotter M, Inkster M, Nangle M. Looking to the future: diabetic neuropathy and effects of rosuvastatin on neurovascular function in diabetes models. Diabetes Res Clin Pract 2003;61 Suppl 1:S35-S39.

84. Ahlgren SC, Levine JD. Protein kinase C inhibitors decrease hyperalgesia and C-fiber hyperexcitability in the streptozotocindiabetic rat. J Neurophysiol 1994;72:684-692.

85. Bastyr EJ 3rd, Price KL, Bril V; the MBBQ Study Group. Development and validity testing of the neuropathy total symptom score-6: questionnaire for the study of sensory symptoms of diabetic peripheral neuropathy. Clin Ther 2005;27:1278-1294.

86. Chaplan SR, Bach FW, Pogrel JW, Chung JM, Yaksh TL. Quantitative assessment of tactile allodynia in the rat paw. J Neurosci Methods 1994;53:55-63.

87. Berti-Mattera LN, Kern TS, Siegel RE, Nemet I, Mitchell R. Sulfasalazine blocks the development of tactile allodynia in diabetic rats. Diabetes 2008;57:2801-2808.

88. Takahashi M, Kawaguchi M, Shimada K, Konishi N, Furuya H, Nakashima T. Peri-sciatic administration of indomethacin early after nerve injury can attenuate the development of tactile allodynia in a rat model of L5 single spinal nerve injury. Neurosci Lett 2004;356:37-40.

89. Suzuki R, Rahman W, Hunt SP, Dickenson AH. Descending facilitatory control of mechanically evoked responses is enhanced in deep dorsal horn neurones following peripheral nerve injury. Brain Res 2004;1019:68-76.

90. Gustafsson H, Flood K, Berge OG, Brodin E, Olgart L, Stiller $\mathrm{CO}$. Gabapentin reverses mechanical allodynia induced by sciatic nerve ischemia and formalin-induced nociception in mice. Exp Neurol 2003;182:427-434.

91. Pertovaara A, Wei H, Kalmari J, Ruotsalainen M. Pain behavior and response properties of spinal dorsal horn neurons following experimental diabetic neuropathy in the rat: modulation by nitecapone, a COMT inhibitor with antioxidant properties. Exp Neurol 2001;167:425-434.

92. Courteix C, Privat AM, Pélissier T, Hernandez A, Eschalier A, Fialip J. Agmatine induces antihyperalgesic effects in diabetic rats and a superadditive interaction with $R(-)$-3-(2-carboxypiperazine-4-yl)-propyl-1-phosphonic acid, a $N$-methyl-D-aspartate-receptor antagonist. J Pharmacol Exp Ther 2007;322:12371245.

93. Arreola-Espino R, Urquiza-Marín H, Ambriz-Tututi M, et al. Melatonin reduces formalin-induced nociception and tactile allodynia in diabetic rats. Eur J Pharmacol 2007;577:203-210.

94. Sánchez-Ramírez GM, Caram-Salas NL, Rocha-González HI, et al. Benfotiamine relieves inflammatory and neuropathic pain in rats. Eur J Pharmacol 2006;530:48-53.

95. Ulugol A, Karadag HC, Ipci Y, Tamer M, Dokmeci I. The effect of WIN 55,212-2, a cannabinoid agonist, on tactile allodynia in diabetic rats. Neurosci Lett 2004;371:167-170.

96. Jolivalt CG, Mizisin LM, Nelson A, et al. B vitamins alleviate indices of neuropathic pain in diabetic rats. Eur J Pharmacol 2009;612:41-47.

97. Kimura S, Kontani H. Demonstration of antiallodynic effects of the cyclooxygenase-2 inhibitor meloxicam on established diabetic neuropathic pain in mice. J Pharmacol Sci 2009;110:213217.

98. Johnson MS, Ryals JM, Wright DE. Diabetes-induced chemogenic hypoalgesia is paralleled by attenuated stimulus-induced fos expression in the spinal cord of diabetic mice. J Pain 2007; 8:637-649. 
99. Ramos KM, Jiang Y, Svensson CI, Calcutt NA. Pathogenesis of spinally mediated hyperalgesia in diabetes. Diabetes 2007;56: $1569-1576$.

100. Jolivalt CG, Vu Y, Mizisin LM, Mizisin AP, Calcutt NA. Impaired prosaposin secretion during nerve regeneration in diabetic rats and protection of nerve regeneration by a prosaposin-derived peptide. J Neuropathol Exp Neurol 2008;67:702-710.

101. Jolivalt CG, Lee CA, Ramos KM, Calcutt NA. Allodynia and hyperalgesia in diabetic rats are mediated by GABA and depletion of spinal potassium-chloride co-transporters. Pain 2008;140: $48-57$.

102. Calcutt NA, Li L, Yaksh TL, Malmberg AB. Different effects of two aldose reductase inhibitors on nociception and prostaglandin E. Eur J Pharmacol 1995;285:189-197.

103. Calcutt NA, Jorge MC, Yaksh TL, Chaplan SR. Tactile allodynia and formalin hyperalgesia in streptozotocin-diabetic rats: effects of insulin, aldose reductase inhibition and lidocaine. Pain 1996; 68:293-299.

104. Ceseña RM, Calcutt NA. Gabapentin prevents hyperalgesia during the formalin test in diabetic rats. Neurosci Lett 1999;262:101104.

105. Hotta N, Toyota T, Matsuoka K, et al.; SNK-860 Diabetic Neuropathy Study Group. Clinical efficacy of fidarestat, a novel aldose reductase inhibitor, for diabetic peripheral neuropathy: a 52-week multicenter placebo-controlled double-blind parallel group study [Erratum in: Diabetes Care 2002;25:413-4]. Diabetes Care 2001;24:1776-1782.

106. Hotta N, Akanuma Y, Kawamori R, et al. Long-term clinical effects of epalrestat, an aldose reductase inhibitor, on diabetic peripheral neuropathy: the 3-year, multicenter, comparative Aldose Reductase Inhibitor-Diabetes Complications Trial. Diabetes Care 2006;29:1538-1544.

107. Hotta N, Yasuda K, Sumita Y, et al. Effects of a novel aldose reductase inhibitor, fidarestat (SNK-860), on vibration perception threshold and subjective symptoms in patients with diabetic polyneuropathy: an open-label pilot study. Clin Drug Investig 2004; 24:671-680.

108. Bril V, Buchanan RA. Long-term effects of ranirestat (AS-3201) on peripheral nerve function in patients with diabetic sensorimotor polyneuropathy. Diabetes Care 2006;29:68-72.

109. Kles KA, Vinik AI. Pathophysiology and treatment of diabetic peripheral neuropathy: the case for diabetic neurovascular function as an essential component. Curr Diabetes Rev 2006;2:131145.

110. Casellini CM, Barlow PM, Rice AL, et al. A 6-month, randomized, double-masked, placebo-controlled study evaluating the effects of the protein kinase $C-\beta$ inhibitor ruboxistaurin on skin microvascular blood flow and other measures of diabetic peripheral neuropathy. Diabetes Care 2007;30:896-902.

111. Ametov AS, Barinov A, Dyck PJ, et al.; SYDNEY Trial Study Group. The sensory symptoms of diabetic polyneuropathy are improved with $\alpha$-lipoic acid: the SYDNEY trial [Erratum in: Diabetes Care 2003;26:2227]. Diabetes Care 2003;26:770-776.

112. Ziegler D, Ametov A, Barinov A, et al. Oral treatment with $\alpha$-lipoic acid improves symptomatic diabetic polyneuropathy: the SYDNEY 2 trial. Diabetes Care 2006;29:2365-2370.

113. Ekberg K, Brismar T, Johansson BL, et al. C-Peptide replacement therapy and sensory nerve function in type 1 diabetic neuropathy. Diabetes Care 2007;30:71-76.

114. Reja A, Tesfaye S, Harris ND, Ward JD. Is ACE inhibition with lisinopril helpful in diabetic neuropathy? Diabet Med 1995;12: 307-309.

115. Vinik AI, Tuchman M, Safirstein B, et al. Lamotrigine for treatment of pain associated with diabetic neuropathy: results of two randomized, double-blind, placebo-controlled studies. Pain 2007; 128:169-179.
116. Donofrio PD, Raskin P, Rosenthal NR, et al.; CAPSS-141 Study Group. Safety and effectiveness of topiramate for the management of painful diabetic peripheral neuropathy in an open-label extension study. Clin Ther 2005;27:1420-1431.

117. Wymer JP, Simpson J, Sen D, Bongardt S; Lacosamide SP742 Study Group. Efficacy and safety of lacosamide in diabetic neuropathic pain: an 18-week double-blind placebo-controlled trial of fixed-dose regimens. Clin J Pain 2009;25:376-385.

118. Ropper AH, Gorson KC, Gooch CL, et al. Vascular endothelial growth factor gene transfer for diabetic polyneuropathy: a randomized, double-blinded trial. Ann Neurol 2009;65:386-393.

119. Sang CN, Booher S, Gilron I, Parada S, Max MB. Dextromethorphan and memantine in painful diabetic neuropathy and postherpetic neuralgia: efficacy and dose-response trials. Anesthesiology 2002;96:1053-1061.

120. Somers DL, Clemente FR. The relationship between dorsal horn neurotransmitter content and allodynia in neuropathic rats treated with high-frequency transcutaneous electric nerve stimulation. Arch Phys Med Rehabil 2003;84:1575-1583.

121. Yamamoto T, Hirasawa S, Wroblewska B, et al. Antinociceptive effects of $N$-acetylaspartylglutamate (NAAG) peptidase inhibitors $\mathrm{ZJ}-11, \mathrm{ZJ}-17$ and $\mathrm{ZJ}-43$ in the rat formalin test and in the rat neuropathic pain model. Eur J Neurosci 2004;20:483-494.

122. Obrosova IG, Van Huysen C, Fathallah L, Cao X, Stevens MJ, Greene DA. Evaluation of $\alpha_{1}$-adrenoceptor antagonist on diabetes-induced changes in peripheral nerve function, metabolism, and antioxidative defense. FASEB J 2000;14:1548-1558.

123. Stevens MJ, Obrosova I, Cao X, Van Huysen C, Greene DA. Effects of DL- $\alpha$-lipoic acid on peripheral nerve conduction, blood flow, energy metabolism, and oxidative stress in experimental diabetic neuropathy. Diabetes 2000;49:1006-1015.

124. Perkins BA, Bril V. Emerging therapies for diabetic neuropathy: a clinical overview. Curr Diabetes Rev 2005;1:271-280.

125. Empl M, Renaud S, Erne B, et al. TNF- $\alpha$ expression in painful and nonpainful neuropathies. Neurology 2001;56:1371-1377.

126. Sommer C, Lindenlaub T, Teuteberg P, Schafers M, Hartung T, Toyka KV. Anti-TNF-neutralizing antibodies reduce pain-related behavior in two different mouse models of painful mononeuropathy. Brain Res 2001;913:86-89.

127. Shubayev VI, Myers RR. Endoneurial remodeling by $\mathrm{TNF} \alpha$ - and TNF $\alpha$-releasing proteases: a spatial and temporal co-localization study in painful neuropathy. J Peripher Nerv Syst 2002;7:28-36.

128. Skundric DS, Lisak RP. Role of neuropoietic cytokines in development and progression of diabetic polyneuropathy: from glucose metabolism to neurodegeneration. Exp Diabesity Res 2003;4: 303-312.

129. Satoh J, Yagihashi S, Toyota T. The possible role of tumor necrosis factor- $\alpha$ in diabetic polyneuropathy. Exp Diabesity Res 2003;4:65-71.

130. Pettus BJ, Bielawski J, Porcelli AM, et al. The sphingosine kinase 1/sphingosine-1-phosphate pathway mediates COX-2 induction and $\mathrm{PGE}_{2}$ production in response to TNF- $\alpha$. FASEB J 2003;17: $1411-1421$.

131. Itoh A, Nishihira J, Makita H, Miyamoto K, Yamaguchi E, Nishimura M. Effects of IL- $1 \beta$, TNF- $\alpha$, and macrophage migration inhibitory factor on prostacyclin synthesis in rat pulmonary artery smooth muscle cells. Respirology 2003;8:467-472.

132. Svensson CI, Marsala M, Westerlund A, et al. Activation of $\mathrm{p} 38$ mitogen-activated protein kinase in spinal microglia is a critical link in inflammation-induced spinal pain processing. J Neurochem 2003;86:1534-1544.

133. Myers RR, Sekiguchi Y, Kikuchi S, et al. Inhibition of p38 MAP kinase activity enhances axonal regeneration. Exp Neurol 2003; 184:606-614.

134. Wallace MS. Calcium and sodium channel antagonists for the treatment of pain. Clin J Pain 2000;16(2 Suppl):S80-S85. 